

\title{
Strengthening strategy for a ductile metastable $\beta$-titanium alloy using low-temperature aging
}

F. Sun, Jin-Ying Zhang, P. Vermaut, D. Choudhuri, T. Alam, S.A. Mantri, P. Svec, T. Gloriant, P.J. Jacques, R. Banerjee, et al.

\section{- To cite this version:}

F. Sun, Jin-Ying Zhang, P. Vermaut, D. Choudhuri, T. Alam, et al.. Strengthening strategy for a ductile metastable $\beta$-titanium alloy using low-temperature aging. Materials Research Letters, 2017, 5 (8), pp.547-553. 10.1080/21663831.2017.1350211 . hal-01639686

\section{HAL Id: hal-01639686}

https://hal-univ-rennes1.archives-ouvertes.fr/hal-01639686

Submitted on 27 Jun 2018

HAL is a multi-disciplinary open access archive for the deposit and dissemination of scientific research documents, whether they are published or not. The documents may come from teaching and research institutions in France or abroad, or from public or private research centers.
L'archive ouverte pluridisciplinaire HAL, est destinée au dépôt et à la diffusion de documents scientifiques de niveau recherche, publiés ou non, émanant des établissements d'enseignement et de recherche français ou étrangers, des laboratoires publics ou privés.

\section{(c)(1)}

Distributed under a Creative Commons Attribution| 4.0 International License 


\title{
Strengthening strategy for a ductile metastable $\beta$-titanium alloy using low-temperature aging
}

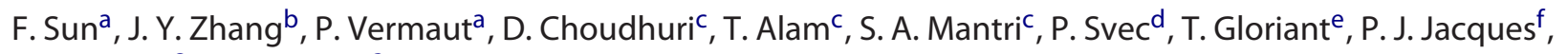 \\ R. Banerjee ${ }^{C}$ and F. Prima ${ }^{a}$

 \\ Engineering, China University of Mining and Technology, Xuzhou, People's Republic of China; 'Department of Materials Science and

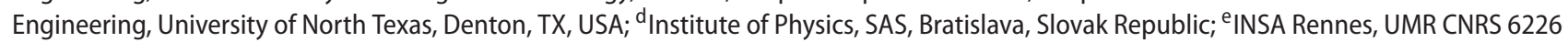 \\ ISCR/Chimie-Métallurgie, Rennes cedex 7, France; ${ }^{\mathrm{f}}$ Materials and Civil Engineering, Institute of Mechanics, IMAP, Université Catholique de \\ Louvain, Louvain-la-Neuve, Belgium
}

\begin{abstract}
While $\omega$ precipitates in metastable $\beta$ titanium alloys are typically considered embrittling and consequently deleterious to the mechanical properties, this paper demonstrates that low-temperature aging (LTA) treatments for short time periods can in fact enhance the yield strength while preserving substantial elongation-to-failure in $\omega$ containing $\beta$ titanium alloys. LTA treatments, carried out on a ductile $\beta$ metastable Ti-12Mo alloy, significantly improve the yield strength of the material ( $\sim 55 \%$ increase as compared to solution-treated samples) while keeping both TRIP/TWIP effects and a large elongation-to-failure ( $\varepsilon=0.4$ in true strain), resulting in a balance of mechanical properties.
\end{abstract}

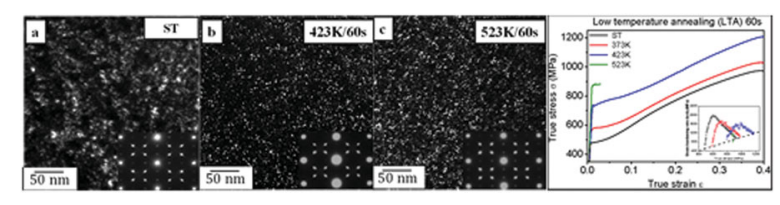

IMPACT STATEMENT

Employing a novel low-temperature annealing strategy, omega precipitates, typically considered embrittling in beta titanium alloys, can effectively increase the yield strength by $50 \%$ while preserving $40 \%$ tensile ductility.

\section{ARTICLE HISTORY}

Received 10 May 2017

\section{KEYWORDS}

$\beta$ titanium alloys; thermal treatment; omega phase; mechanical properties $\beta$ titanium alloys are increasingly used for aerospace, biomedical and automotive applications due to their high strength-to-density ratio $[1,2]$, good hardenability [3] and good corrosion resistance $[1,4]$. The metastable $\beta$ titanium alloys (when obtained by water quenching from the high-temperature $\beta$ region) generally display an increased deformability at room temperature when compared to $\alpha$ and $\alpha / \beta$ titanium alloys [5-7]. However, the poor average ductility of titanium alloys remains a major drawback when compared to steels or $\mathrm{Co}-\mathrm{Cr}$ alloys. Promising results have been recently reached $[3,8,9]$ on a metastable $\beta$ alloy, namely Ti-12Mo (wt\%), displaying an unusual combination of high ductility (with an elongation at fracture of about $\sim 50 \%$ ) and high strain-hardening rate, owing to both stress-induced martensitic transformation and intense mechanical twinning (combined TRIP/TWIP effects).

A complementary challenging question is the definition of strengthening approaches for this family of materials. Indeed, most titanium alloys are usually strengthened through thermo-mechanical treatments involving $\alpha$ precipitation $[2,10]$. However, for metastable TRIP/TWIP alloys such as Ti-12Mo, this classical strategy is no longer suitable after $\alpha$ precipitation, because such precipitation supresses both TRIP and TWIP, by altering $\beta$ phase stability (with respect to twinning and formation of martensites) with solute partitioning [11]. Therefore, the development of alternative strengthening pathways is currently needed.

CONTACT R. Banerjee rajarshi.banerjee@unt.edu Department of Materials Science and Engineering, University of North Texas, Denton, TX 76207, France 
Since it is well known that the level of chemical instability of the $\beta$ matrix is critical with respect to the activation of stress-induced phase transformations and mechanical twinning $[6,12]$, our approach for strengthening is actually based on low-temperature thermal treatments in the isothermal $\omega$ precipitation range [13]. The double objective is to promote precipitation strengthening through fully coherent $\omega$ phase nucleation, but without excessive modification of the $\beta$ matrix chemical composition, therefore maintaining both TRIP and TWIP effects as the main deformation mechanisms. This work is based on two key experimental observations reported in the literature: (1) it was previously reported that the nucleation stage of the $\omega$ phase is almost instantaneous at a given temperature [14], whereas growth depends on time and is accompanied by exodiffusion of alloying elements from growing $\omega$ particles to the surrounding $\beta$ matrix [14,15]; and (2) the mechanical properties of $\beta$ titanium alloys drastically depend on the isothermal $\omega$ volume fraction, resulting in a drastic embrittlement after long time aging [16]. Consequently, low-temperature aging (LTA) treatments have been performed in this work, that is, very short treatment times of $60 \mathrm{~s}$ to promote nucleation of the $\omega$ phase without subsequent growth and to keep the initial $\beta$ matrix stability. As a result, a large increase in the yield strength without a decrease in the ductility is expected from this approach.

The binary Ti-12 wt\%Mo (hereafter referred to as Ti-12Mo) alloy was fabricated by vacuum arc melting using pure $\mathrm{Ti}$ and Mo. The chemical composition of the bulk ingot was determined to be (in wt.\%): $\mathrm{Mo}-12.3 \%, \mathrm{Fe}-0.02 \%, \mathrm{H}-0.004 \%, \mathrm{O}-0.06 \%$, $\mathrm{N}-0.004 \%, \mathrm{C}-0.011 \%$ and $\mathrm{Ti}-$ balance. Ingots were heavily cold rolled to $95 \%$ thickness reduction. The coldrolled sheets were solution-treated (ST) at $1173 \mathrm{~K}$ for $1.8 \mathrm{ks}$ and subsequently water-quenched. The microstructure of solution-treated $\mathrm{Ti}-12 \mathrm{Mo}$ samples consists of a single-phase metastable $\beta$ matrix with a dispersion of quenched-in $\omega_{\text {ath }}$ nano-precipitates $[8,9]$.

Three different LTA temperatures have been selected from resistometric measurements [13], presumably at the onset ( 373 and $423 \mathrm{~K}$ ) and the end $(523 \mathrm{~K})$ of the $\omega_{\text {iso }}$ precipitation range, in order to obtain various nucleation rates of $\omega_{\text {iso. The LTA treatment was }}$ conducted by sealing the tensile specimens in special copper modules, pre-heated to the annealing temperature. The copper modules were designed to ensure rapid heat transfer and a uniform temperature distribution. The LTA temperatures were monitored by two thermocouples located in contact with the specimen and at the heating source, respectively. The temperature feedbacks are managed by Nabertherm ${ }^{\circledR}$ thermal system to maintain the LTA treatment $\left(T \pm 2^{\circ} \mathrm{C}\right)$. The heating rate was of the order of $20^{\circ} \mathrm{C} / \mathrm{s}$ and water quenching was applied for rapid cooling. The true stress-strain curves of LTA-treated specimens were obtained by uniaxial tensile tests at room temperature on an INSTRON 5966 machine, at a constant strain rate of $\dot{\varepsilon}=10^{-3} \mathrm{~s}^{-1}$. The tensile specimens were machined from rolled sheets with gauge dimensions of $40 \mathrm{~mm}$ (length) $\times 4 \mathrm{~mm}$ (width) $\times 0.5 \mathrm{~mm}$ (thickness). The high-precision extensometer (Instron 2630-100 series) was used to measure the tensile strain. A batch of five specimens were tested for each condition, showing reliable reproducibility (stress variation $< \pm 5 \%$, strain variation $< \pm 10 \%)$. Young's moduli $(E)$ were calculated at $\varepsilon=0.02-0.5 \%: E_{\mathrm{ST}}=84 \pm 3 \mathrm{GPa}, E_{373 \mathrm{~K}}=86 \pm 3 \mathrm{GPa}$, $E_{423 \mathrm{~K}}=87 \pm 5 \mathrm{GPa}$ and $E_{523 \mathrm{~K}}=89 \pm 2 \mathrm{GPa}$. One representative curve for each batch of samples has been shown in this paper. Atom probe tomography (APT) analysis was carried out in order to highlight potential solute partitioning after LTA treatment. The APT experiments were conducted using an LEAP 3000X HR local electrode atom probe system from Cameca Instruments Inc. Data analysis was performed using the IVAS 3.6.10 software. EBSD characterization was performed on the plane defined by the rolling direction and traverse direction using a NORDIF system on an FEG-SEM platform (Zeiss Leo1530). Areas of $300 \mu \mathrm{m} \times 300 \mu \mathrm{m}$ were mapped with a step size of $210 \mathrm{~nm}$. The data were processed using TSL OIM software. A JEOL 2000FX transmission electron microscope (TEM) operating at $200 \mathrm{kV}$ was used for microstructural analysis at the submicrometric scale.

LTA samples microstructures have been investigated by both TEM and APT and compared to the solutiontreated microstructure. TEM dark-field images from solution-treated (1173 K/1.8 ks), LTA $423 \mathrm{~K} / 60 \mathrm{~s}$ and LTA $523 \mathrm{~K} / 60 \mathrm{~s} \mathrm{Ti}-12 \mathrm{Mo}$ samples (Figure 1) clearly show different variants of the $\omega$ precipitates distributed uniformly throughout the $\beta$ matrix (recorded by selecting all the four $\omega$ reflections). A homogeneous distribution of fine-scale athermal $\omega$ precipitates are observed in the solution-treated sample (Figure 1(a)).

The exact morphology of these nanometer scale $\omega$ precipitates, and their volume fraction, is difficult to determine based on these dark-field images due to resolution issues, and the overlap of multiple $\omega$ precipitates through the foil thickness. The corresponding selected area diffraction patterns (inset) clearly show, in addition to the fundamental reflections arising from the $\beta$ matrix, additional reflections at $1 / 3$ and $2 / 3\left\{\begin{array}{lll}1 & 1 & 2\end{array}\right\} \beta$ positions, attributable to the $\omega$ phase. A rigorous determination of the $\omega$ volume fraction in these samples is rather difficult, and requires synchrotron-based x-ray diffraction data, which is presently not available for these samples. 


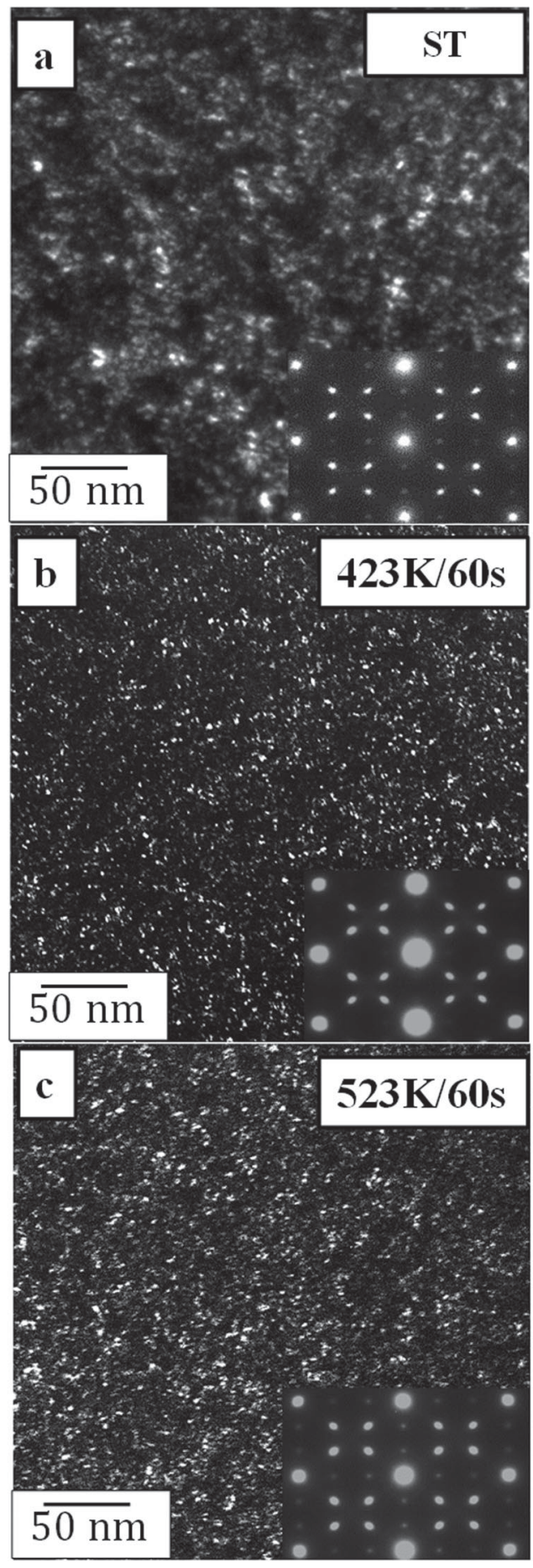

Figure 1. Dark-field TEM images showing fine-scale $\omega$ precipitates within the $\beta$ matrix, and corresponding [011] $\beta$ zone axis electron diffraction patterns from: (a) solution-treated condition, (b) LTA at $423 \mathrm{~K}$ for $60 \mathrm{~s}$, (c) LTA at $523 \mathrm{~K}$ for $60 \mathrm{~s}$. The dark-field images in all three cases have been recorded with diffracted spots from multiple $\omega$ variants.

An approximate evaluation of the $\omega$ volume fraction has been attempted using selected area electron diffraction patterns, such as the $[110] \beta$ zone axis patterns, shown as insets in Figure 1(a)-(c). The ratio of intensities of appropriate $\omega$ reflections to that of $\beta$ reflections was calculated and compared in all three cases. While this ratio is not a direct measure of the $\omega$ volume fraction, it can be used for relative comparison between the three different conditions. However, these intensity ratios neither exhibited any systematic variations nor were largely different (not statistically relevant). In the solution-treated $\mathrm{Ti}-12 \mathrm{Mo}$ alloy, it is worth noting that only sharp/discreet $\omega$ reflections can be seen, without any diffuse scattering or reciprocal lattice streaking. This is likely to be a consequence of the fully collapsed $\{111\} \beta$ of the athermal $\omega$ phase (displaying $\mathrm{P} 6 / \mathrm{mmm}$ symmetry), consistent with the atomic arrangements clearly visible in the atomic resolution HAADF-STEM images of athermal $\omega$ precipitates in Ti-12Mo [17]. After LTA treatments at $423 \mathrm{~K}$ (Figure 1(b)) and $523 \mathrm{~K}$ (Figure 1(c)) for 60 s, dark-field TEM images display $\omega$ precipitates in the $2-5 \mathrm{~nm}$ size range. Based on the dark-field TEM images shown in Figure 1(a)-(c), any significant change in the density of $\omega$ precipitates between these three conditions was not discernible.

Compositional changes during the LTA treatments were investigated using APT. The volume of each APT analysis was at least $40 \mathrm{~nm} \times 40 \mathrm{~nm} \times 70 \mathrm{~nm}$. Compositional partitioning or phase separation in the APT datasets was carried out by dividing each dataset into volume elements (or voxels) containing 100 atoms, then plotting the distribution of the frequency versus composition in each case. The experimental plots were compared with a standard binomial function, which would correspond to a completely random distribution of atoms. The experimental frequency distribution plots and the corresponding binomials are shown in Figure 2.

The experimentally observed distributions shown in Figure 2(a,b) are almost identical to the calculated ones for a perfectly random solid solution (standard binomial distribution). It clearly indicates that there is minimal, if any, compositional segregation or partitioning within the solution-treated $\mathrm{Ti}-12 \mathrm{Mo}$ alloy and the $423 \mathrm{~K} / 60 \mathrm{~s}$ LTA samples. However, early stages of compositional partitioning or phase separation are observed in case of the LTA $523 \mathrm{~K} / 60 \mathrm{~s}$ treated sample. These local composition variations may correspond to the early stage of $\omega_{\text {iso }}$ growth accompanied by a rejection of Mo solute atoms from the growing $\omega_{\text {iso }}$ precipitates into the surrounding $\beta$ matrix. Furthermore, based on the APT results from solution-treated and subsequently annealed (at 423 and $523 \mathrm{~K})$ specimens, one can assume minimal partitioning after $373 \mathrm{~K} / 60 \mathrm{~s}$. Regardless, the APT results yield two interesting observations: (i) in the early stages of annealing at $423 \mathrm{~K}$ solute rejection is practically indiscernible and (ii) solute partitioning accompanying isothermal $\omega$ growth is almost immediate (within 60 s) at $523 \mathrm{~K}$. 


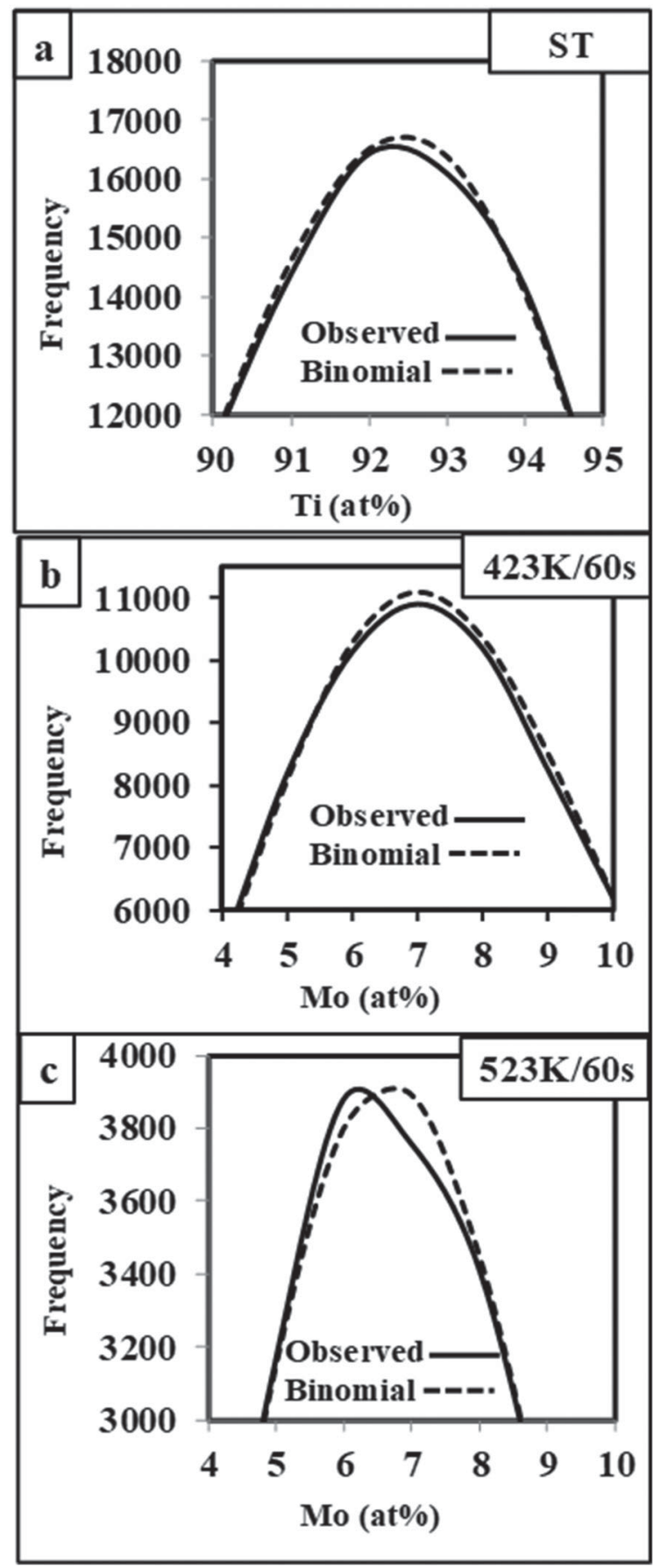

Figure 2. The analyzed APT data corresponding to the tendency for phase separation in each of the three samples; solution-treated (a), $423 \mathrm{~K} / 60 \mathrm{~s}$ annealed (b), and $523 \mathrm{~K} / 60 \mathrm{~s}$ annealed (c). Each plot shows the frequency distribution of 100 atom packets, sampled from the total number of atoms within the APT reconstruction, as a function of their composition (in terms of at.\% Mo).

The mechanical behaviour of the LTA specimens was investigated by uniaxial tensile tests at room temperature. The true stress $(\sigma)$-strain $(\varepsilon)$ curves of the LTA specimens are plotted in Figure 3 and compared to the solution-treated ones. Interestingly, it can be observed that LTA treatments for $60 \mathrm{~s}$ at 373 and $423 \mathrm{~K}$

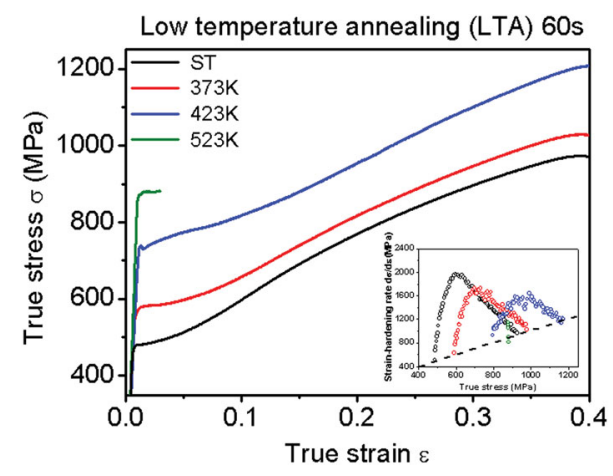

Figure 3. True strain-true stress tensile curves of the ST specimen and LTA specimens. The corresponding strain-hardening rates are shown in the inset figure.

substantially enhance the yield strength while retaining the initial ductility of the ST samples. In the $373 \mathrm{~K}$ treated specimens, the beneficial effect on yield strength is observed to be quite moderate with respect to the ST state. However, in the $423 \mathrm{~K}$ treated specimens, a significant jump of yield strength from 480 to $730 \mathrm{MPa}$ is observed, still retaining the initial ductility. For these two LTA temperatures, a slight decrease in strain-hardening rate is progressively noticed (inset of Figure 3 ) and seems to be associated with the disappearance of the stress plateau on the onset of the plastic range. This plateau has previously been related to the stress-induced $\alpha^{\prime \prime}$ precipitation which is shown to be involved in the strainhardening mechanisms in ST Ti-12Mo [8-9]. Therefore, this might be a strong indication of a progressive change in the activated deformation mechanisms after LTA treatments. After LTA at $523 \mathrm{~K}$, it was observed that the mechanical behaviour has drastically changed; involving a further increase in the yield strength, but accompanied by a drastic reduction in ductility (dropping from more than $40 \%$ to around $3 \%$ ).

These observations lead to some important questions regarding the role of $\omega$ precipitates on the deformation behaviour of metastable $\beta(+\omega)$ Ti alloys. It is well accepted that $\omega$ precipitates typically cause embrittlement of these alloys. However, the fact that the embrittlement is usually caused by the isothermal $\omega$ phase (which is solute-depleted in comparison to the surrounding $\beta$ matrix) is often not discussed in the literature. Additionally, the restriction of the dislocation slip length in the $\beta$ matrix (related to the huge density of $\omega$ precipitates) also enhances the strength but reduces the ductility. Since the $\omega / \beta$ interface remains coherent, the elastic energy might play a significant role on the mechanical properties in Ti-Mo alloys. During the isothermal growth of $\omega$ precipitates, the precipitate/matrix interface is thus likely to show a high degree of coherency, which results in elastic strain fields and consequent hardening 
LTA $423 \mathrm{~K} / 60 \mathrm{~s}(\varepsilon=0.05)$


\section{LTA $523 \mathrm{~K} / 60 \mathrm{~s}(\varepsilon=0.03)$}
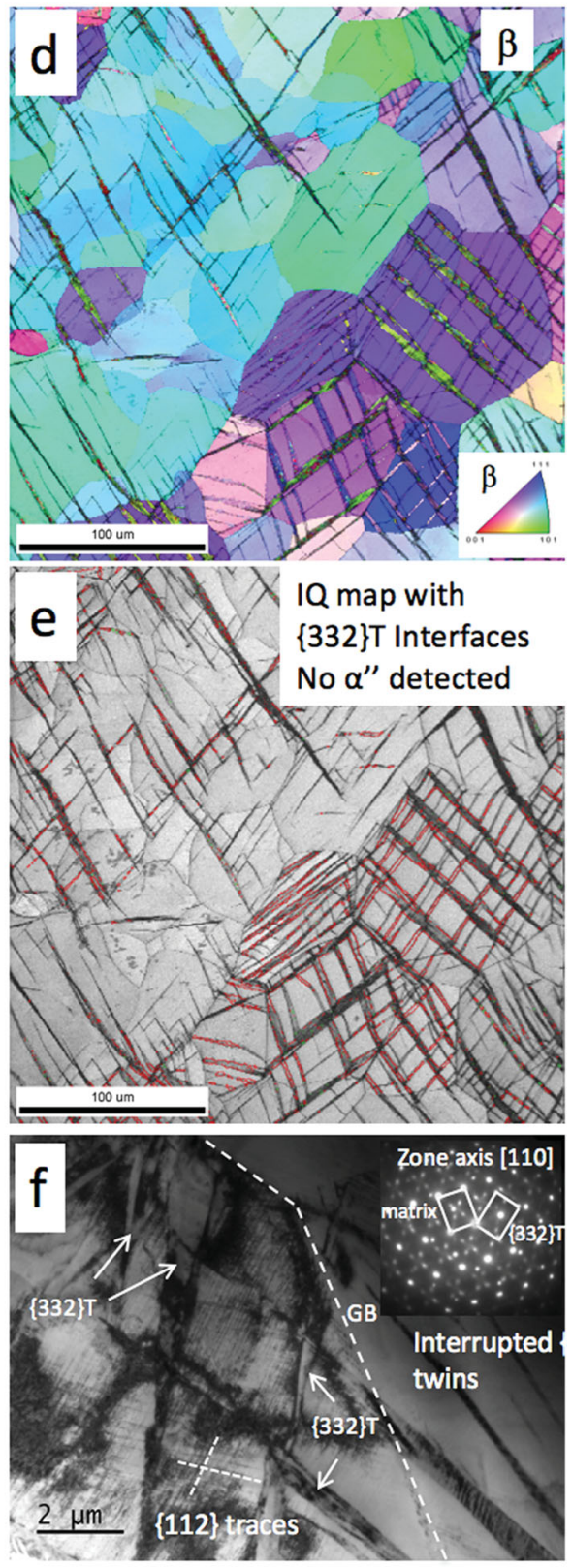

Figure 4. EBSD and TEM observations after tensile deformation LTA. $423 \mathrm{~K}(\varepsilon=0.05)$ : (a) IPF + IQ mapping of $\beta+\alpha^{\prime \prime}$ phases, (b) IQ map with $\{332\}$ twinning interfaces (red) and $\alpha^{\prime \prime}$ IPF mapping (indicated by white arrows), (c) TEM bright field image of complex $\{332\}$ and $\{112\}$ twins. LTA $523 \mathrm{~K}$ (rupture $\varepsilon=0.03$ ): (d) IPF + IQ mapping of $\beta$ phase, no $\alpha^{\prime \prime}$ phase detected, (e) IQ map with $\{332\}$ twinning interfaces (red), and (f) TEM bright field image of interrupted $\{332\}$ twins.

of the surrounding $\beta$ matrix. As shown here, the very fine athermal $\omega$ phase in the as-quenched $\beta$ phase does not induce any brittleness, even in case of commensurate athermal $\omega$ precipitates (fully collapsed $\{111\} b c c$ planes). However, it can be conjectured that the growth of these $\omega$ precipitates accompanied by the rejection of Mo (onset of isothermal $\omega$ precipitation) is mainly controlled (stabilized) by elastic strain, as in many metallic systems with embedded coherent nanoparticles [18]. As the $\omega$ precipitates grow and the transition from athermal to isothermal precipitates occurs, the local elastic strains rapidly increase prior to any detectable partitioning of Mo based on the APT results. The onset of Mo partitioning between $\omega$ and $\beta$ phases, accompanied with the rapid increase in coherency strains, is very detrimental for $\beta$-phase ductility as observed for the $523 \mathrm{~K} / 60 \mathrm{~s}$ LTA specimen. Regarding the specific TRIP/TWIP properties, the $523 \mathrm{~K} / 60 \mathrm{~s}$ LTA specimen displays a drastic 
drop of ductility which is presumably due to: (i) a strong increase in critical resolved shear stress regarding the different deformation mechanisms in the $\beta$ matrix; and (ii) a tendency for local chemical stabilization from the exodiffusion of Mo atoms from $\omega_{\text {iso }}$ to $\beta$, with a subsequent drop of Ms temperature of the $\beta$ phase.

To investigate the deformation mechanisms, EBSD observations were performed on deformed (strain, $\varepsilon=0.05)$ specimens treated at $423 \mathrm{~K}$ for $60 \mathrm{~s}$ (Figure $4(\mathrm{a}, \mathrm{b})$ ) and at $523 \mathrm{~K}$ (rupture, $\varepsilon=0.03$ ) for $60 \mathrm{~s}$ (Figure 4(d,e)). TEM bright field images (shown in Figure $4(\mathrm{c}, \mathrm{f}))$ complete the characterization at a finer scale. The $423 \mathrm{~K} / 60 \mathrm{~s}$ treated specimen exhibits a deformation microstructure composed of dense mechanical $\{332\}<113>$ type $\beta$ twinning (almost $100 \%$ of the grains are twinned) accompanied by a small volume fraction of stress-induced orthorhombic $\alpha^{\prime \prime}$ phase. Inside the primary $\beta$ twins, secondary twinning was also observed by TEM bright field (Figure 4(c)). Fine-scale (not visible in EBSD) $\{112\}<111>$ type twins are also observed in this sample. These observations for a $423 \mathrm{~K} / 60 \mathrm{~s}$ treated specimen are consistent with the stress-strain curves shown in Figure 3 since the deformation mechanisms are quite similar to those observed in the $\mathrm{Ti}-12 \mathrm{Mo}$ in the solution-treated state $[8,9]$. This results in a large uniform straining and a high strain-hardening rate as observed in Figure 3. On the deformed $523 \mathrm{~K} / 60 \mathrm{~s}$ aged sample, EBSD highlights a much smaller volume fraction of $\{332\}<113>$ type mechanical twins, at a much finer length scale. It is worth noting that most of the observed twins do not generally propagate through whole grains and that mechanical twins do not nucleate in $100 \%$ of the grains. The presence of stress-induced $\alpha^{\prime \prime}$ could not be detected even in small volume fraction. At the early stages of precipitation, the $\omega$ phase within the $\beta$ matrix of titanium alloys can potentially be a useful 'means' for strengthening without any significant loss of ductility. This high strengthening potential is particularly applicable to strain-transformable titanium alloys. It has been shown that the combined TRIP/TWIP effects can be preserved when the chemical stability of the $\beta$ matrix remains unchanged (when using very short aging times). The solution-treated and quenched alloy consists of compositionally congruent athermal $\omega$ precipitates. The experimental evidence suggests that at the early stages of isothermal aging, there is a change in the internal strain field of the $\beta$ matrix, presumably due to the early stages of growth of coherent athermal $\omega$ precipitates, prior to any significant compositional partitioning between these two phases. Subsequent $\omega$ growth accompanied by experimentally discernible compositional partitioning leads to a drastic loss of ductility. While these results are interesting, more detailed investigations such as in situ resistivity measurement and in situ tensile test in TEM are required in order to understand the mechanism of transition from congruent athermal $\omega$ to isothermal $\omega$ precipitates, and its consequent influence on the elastic strain fields within the $\beta$ matrix. Nevertheless, these results open up a new avenue in terms of exploiting $\omega$ precipitation in titanium alloys as potent strengthening mechanism, while retaining substantial ductility.

\section{Disclosure statement}

No potential conflict of interest was reported by the authors.

\section{Funding}

Support by the projects (Agentúra na Podporu Výskumu a Vývoja) APVV-0460-12 and APVV-15-0621 is acknowledged.

\section{References}

[1] Williams J, Starke E. Progress in structural materials for aerospace systems. Acta Mater. 2003;51(19):5775-5799.

[2] Ivasishin O, Markovsky P, Matviychuk Y, et al. A comparative study of the mechanical properties of high-strength $\beta$-titanium alloys. J Alloys Compd. 2008;457(1-2): 296-309.

[3] Sun F, Prima F, Gloriant T. High-strength nanostructured $\mathrm{Ti}-12 \mathrm{Mo}$ alloy from ductile metastable beta state precursor. Mater Sci Eng. 2010;527(16-17):4262-4269.

[4] Niemeyer T, Grandini C, Pinto L, et al. Corrosion behavior of Ti-13Nb-13Zr alloy used as a biomaterial. J Alloys Compd. 2009;476(1-2):172-175.

[5] Grosdidier T, Combres Y, Gautier E, et al. Effect of microstructure variations on the formation of deformationinduced martensite and associated tensile properties in a $\beta$ metastable Ti alloy. Metall Mater Trans A. 2000;31(4):1095-1106.

[6] Brozek C, Sun F, Vermaut P, et al. A $\beta$-titanium alloy with extra high strain-hardening rate: design and mechanical properties. Scr Mater. 2016;114:60-64.

[7] Gloriant T, Texier G, Sun F, et al. Characterization of nanophase precipitation in a metastable $\beta$ titanium-based alloy by electrical resistivity, dilatometry and neutron diffraction. Scr Mater. 2008;58(4):271-274.

[8] Marteleur M, Sun F, Gloriant T, et al. On the design of new $\beta$-metastable titanium alloys with improved work hardening rate thanks to simultaneous TRIP and TWIP effects. Scr Mater. 2012;66(10):749-752.

[9] Sun F, Zhang J, Marteleur M, et al. Investigation of early stage deformation mechanisms in a metastable $\beta$ titanium alloy showing combined twinning-induced plasticity and transformation-induced plasticity effects. Acta Mater. 2013;61(17):6406-6417.

[10] Weiss I, Semiatin S. Thermomechanical processing of beta titanium alloys-an overview. Mater Sci Eng A. 1998;243(1-2):46-65.

[11] Mantri S, Choudhuri D, Alam T, et al. Change in the deformation mode resulting from beta-omega compositional partitioning in a Ti-Mo alloy: room versus elevated temperature. Scr Mater. 2017;130:69-73.

[12] Hida M, Sukedai E, Henmi C, et al. Stress induced products and ductility due to lattice instability of $\beta$ 
phase single crystal of Ti-Mo alloys. Acta Metall. 1982;30(8):1471-1479.

[13] Sun F, Nowak S, Gloriant T, et al. Influence of a short thermal treatment on the superelastic properties of a titanium-based alloy. Scr Mater. 2010;63(11): 1053-1056.

[14] Prima F, Debuigne J, Boliveau M, et al. Control of omega phase volume fraction precipitated in a beta titanium alloy: development of an experimental method. J Mater Sci Lett. 2000;19(24):2219-2221.

[15] Devaraj A, Nag S, Srinivasan R, et al. Experimental evidence of concurrent compositional and structural instabilities leading to $\omega$ precipitation in titaniummolybdenum alloys. Acta Mater. 2012;60(2):596609.

[16] Gysler A, Lutjering G, Gerold V. Deformation behavior of age-hardened Ti-Mo alloys. Acta Metall. 1974;22(7): 901-909.

[17] Zheng Y, Banerjee D, Fraser H. A nano-scale instability in the $\beta$ phase of dilute Ti-Mo alloys. Scr Mater. 2016;116:131-134.

[18] Gornostyrev Y, Katsnelson M. Misfit stabilized embedded nanoparticles in metallic alloys. Phys Chem Chem Phys. 2015;17:27249-27257. 